\title{
A CRISE NA EDUCAÇÃO DE HANNAH ARENDT E A CRÍTICA ÀS CONCEPÇÕES EDUCACIONAIS DO PRAGMATISMO
}

\author{
Flávio Rovani de Andrade ${ }^{1}$
}

Resumo: Este artigo procura expor a crítica da filósofa Hannah Arendt (1906-1975) às concepções educacionais do Pragmatismo, em especial ao pragmatismo de John Dewey (1859-1952). Primeiramente, é exposta brevemente a teoria educacional de Hannah Arendt com base no texto A crise na educação, seu único texto eminentemente educacional. Por se articular com o todo de sua obra, faz-se também incursões na vasta obra da autora, a fim de ampliar a compreensão do sentido da educação no conjunto da filosofia e da teoria política arendtiana. Posteriormente, é tratada a crítica objeto deste artigo, propriamente dita, com base numa análise do texto Democracia e Educação, de Dewey, à luz da teoria arendtiana.

Palavras-chave: educação, liberdade, tradição, autoridade, Hannah Arendt, Pragmatismo.

"Não se pode educar sem ao mesmo tempo ensinar; uma educação sem aprendizagem é vazia e portanto se degenera, com muita facilidade, em retórica moral e emocional."

HANNAH ARENDT

O texto educacional de Hannah Arendt (2000), A crise na educação, parte da coletânea Entre o passado e o futuro, compõe-se de quatro partes. Na primeira, grosso modo, é contextualizada a crise no sistema educacional dos EUA, tendo em vista por um lado ser ela participante da crise geral que acometeu o mundo moderno, e por outro considerando a educação face à existência histórica e política do país, ou nas palavras de Arendt (2000), “enraizada na atitude política do país". Nesse último aspecto, destaca o entusiasmo pelo novo e pela igualdade como elemento intensificador da crise que, somado à aceitação servil e indiscriminada de modernas teorias pedagógicas, tornam a crise ainda mais aguda.

Assim, o que torna a crise educacional na América tão particularmente aguda é o temperamento político do país, que espontaneamente peleja para igualar ou apagar tanto quanto possível as diferenças entre jovens e velhos, entre dotados e pouco dotados, entre crianças e adultos e, particularmente, entre alunos e professores. É óbvio que um nivelamento desse tipo só pode

\footnotetext{
${ }^{1}$ Graduado em Filosofia pelo Centro Universitário Assunção (UNIFAI). Mestre em Educação, eixo temático Filosofia da Educação, pela Faculdade de Educação da Universidade de São Paulo (FEUSP). Professor do curso de Filosofia do UNIFAI. E-mail: flaviorovani@ usp.br.
} 
ser efetivamente consumado às custas da autoridade do mestre ou às expensas daquele que é mais dotado entre os estudantes [...] Em todo caso, esses fatores gerais não podem explicar a crise [na educação] que nos encontramos presentemente, nem tampouco justificam as medidas que as precipitam (ARENDT, 2000, p. 229).

Por não poder tal "temperamento político" justificar medidas educativas equivocadas, Arendt passa à segunda parte do texto, na qual explicita e analisa os três pressupostos básicos que, segundo ela, fundamentam essas medidas. O primeiro pressuposto é a existência de um mundo e uma sociedade infantis autônomos, que por isso devem ser governados pelas crianças. O segundo pressuposto, influenciado pela Psicologia e por princípios do Pragmatismo, consiste na pedagogia tornada ciência do ensino em geral, emancipando-se da matéria a ser ensinada. $\mathrm{O}$ segundo pressuposto é ligado ao ensino, o terceiro à aprendizagem. A Pedagogia e as escolas de professores negligentes quanto ao conteúdo da formação docente só foram possíveis graças a uma moderna teoria sobre a aprendizagem, consistindo em uma aplicação do terceiro pressuposto, que no dizer de Arendt (2000, p. 231-232), encontrou “expressão conceitual sistemática no Pragmatismo". Tal pressuposto é que só se conhece e compreende o que se faz, aplicando-se à educação na substituição do aprendizado pelo fazer. Esses pressupostos, que não são intensificadores, mas vias de fato da crise educacional, trazem cada um problemas distintos, tendo todos relação com a crítica arenditiana ao Pragmatismo.

De maneira geral, na terceira e na quarta partes, é analisada a crise na educação à luz da própria teoria da autora, focando centralmente a crise da autoridade e da tradição, visto que a crise na educação, que passa pelo tratado nas partes anteriores, relaciona-se à ruptura com a tradição e à perda da autoridade.

A fim de que se possa cercar tanto a teoria educacional quanto a crítica ao Pragmatismo elaboradas por Hannah Arendt, a seguir será exposta a primeira, mapeando alguns dos conceitos-chave de seu pensamento e, posteriormente, tratar-se-á mais especificamente da segunda.

\section{Do sentido da educação em Hannah Arendt}

Já se tornou clássica a definição que a filósofa Hannah Arendt (2000) empresta à educação, em seu texto A crise na educação. O referido texto, publicado inicialmente em 1958, procura abordar a crise na educação dos Estados Unidos nos idos de 1950, assumindo a 
tese de que tal crise é parte de uma crise mais ampla: crise da autoridade, da tradição, da política, do espaço público, da responsabilidade, e que invade a educação.

A célebre definição é a seguinte:

A educação é o ponto em que decidimos se amamos o mundo o bastante para assumirmos a responsabilidade por ele e, com tal gesto, salvá-lo da ruína que seria inevitável não fosse a renovação e a vinda dos novos e dos jovens. A educação é, também, onde decidimos se amamos as nossas crianças o bastante para não expulsá-las do nosso mundo e abandoná-las a seus próprios recursos, e tão pouco arrancar de suas mãos a oportunidade de empreender alguma coisa nova e imprevista para nós, preparando-as em vez disso com antecedência para a tarefa de renovar um mundo comum (ARENDT, 2000, p. 247).

Essa definição traz à luz a função fundamental da educação para a construção do mundo, em Arendt. Vemos articulados conceitos como amor, responsabilidade, renovação, mundo. Se percorremos a obra de Arendt, percebemos que todas essas noções lhes são muito caras, e se são constitutivas da definição de educação, isso significa que ela possui algum grau de centralidade no contexto da obra da autora, ainda que esta não se considere uma especialista em questões educacionais.

Mais ainda, ao percorrermos A crise na educação, encontramos fundamentos filosóficos vigorosos que, participando do pensamento geral da autora, traduzem-se em um modo peculiar e profundo de se conceber a educação.

Arendt (2000) afirma ser a natalidade a essência da educação, o fato de que nascemos para o mundo. Nesse sentido, é importante entender as distinções conceituais que a filósofa faz entre vida e mundo, sendo que nascemos para a vida pelo nascimento e para o mundo pela natalidade: "O mundo - artifício humano - separa a existência do mundo de todo ambiente meramente animal; mas a vida, em si, permanece fora desse mundo artificial, e através da vida o homem permanece ligado a todos os outros organismos vivos" (ARENDT, 1995, p. $10)$.

Arendt (1995), em A Condição Humana, para contemplar a pluralidade das atividades humanas, trabalha com o conceito de vita activa, que compreende três atividades distintas: $\mathrm{O}$ labor, o trabalho e a ação. Essas atividades dizem respeito a diferentes esferas da existência humana. O labor é a atividade mantenedora a vida, que "corresponde ao processo biológico do corpo humano" (ARENDT, 1995, p.15). O trabalho é a atividade produtora dos artifícios humanos que não se encerram na morte, nem são inerentes à natureza, embora passe por cada vida individual, que é sustentáculo da produção artificial; os artifícios transcendem a todas as vidas individuais, pois o mundo transpassa a todas elas. A ação não repousa sobre a natureza 
ou sobre os artifícios criados em sua transformação. "A ação, única atividade que se exerce diretamente entre os homens sem a mediação das coisas ou da matéria, corresponde à condição humana da pluralidade, ao fato de que os homens, e não o homem, vivem na terra e habitam o mundo" (ARENDT, 1995, p. 15). A ação tem por objetivo criar o que Arendt chama de "comunidade política", em que os homens se colocam uns perante os outros para deliberarem sobre os seus rumos, enquanto seres iguais postos como singularidades diante do corpo político coletivo. A condição humana do labor é a vida, do trabalho é a mundanidade e da ação a pluralidade.

As três atividades e suas respectivas condições têm íntima relação com as condições mais gerais da existência humana: o nascimento e a morte, a natalidade e a mortalidade. O labor assegura não somente a sobrevivência do indivíduo, mas a vida da espécie. O trabalho e seu produto, o artefato humano, emprestam certa permanência e durabilidade à futilidade da vida mortal e ao caráter efêmero do tempo humano. A ação, na medida em que se empenha em fundar e preservar corpos políticos, cria a condição para a lembrança, ou seja, para a história (ARENDT, 1995, p. 16-17).

Vê-se que, ao dizer que a natalidade é essência da educação, Arendt nos brinda com um arranjo conceitual bastante abrangente, que envolve várias esferas da vida humana. É pertinente inserir algumas notas. Arendt (2000) não estabelece, de forma direta, nenhuma relação entre os conceitos liberdade e educação, o que não implica em dizer que não haja um teor libertador em sua concepção educacional. Se tomarmos o contexto de Entre o passado e o futuro, o texto educacional insere-se na seqüência de outros ensaios que refletem sobre a tradição, que preserva o mundo, e a liberdade, que o transforma. Isso não é por acaso. A educação se insere nesse meio: entre um mundo que é mais velho do que as crianças e o potencial renovador que cada nova geração traz consigo. Mas deve-se também se reconhecer que embora a assunção da responsabilidade se dê sob a forma da autoridade no ato educativo, educação e liberdade se assentam sobre o fato da natalidade. Diz Arendt (2000, p. 247) que a educação diz respeito à "nossa atitude face ao fato da natalidade: o fato de todos nós virmos ao mundo ao nascermos e de ser o mundo constantemente renovado mediante o nascimento". A natalidade é, como vimos, a essência da educação. A liberdade é a capacidade de iniciar. Ela é propriedade de todo ser humano que veio como novidade ao mundo. "Por constituírem um initium, por serem recém-chegados e iniciadores em virtude do fato de terem nascido, os homens tomam iniciativas, são impelidos a agir” (ARENDT, 1995, p. 190)². A liberdade é,

\footnotetext{
${ }^{2}$ Em Que é Liberdade, texto que antecede A crise na educação, no ínterim da coletânea Entre o passado e o futuro, Arendt, ao interpretar e se apropriar de parte da teoria agostiniana da liberdade - que para ela traduz muito mais o Agostinho romano do que propriamente o cristão, por ser ele um romano - faz afirmações muito
} 
para Arendt (2000, p. 220), um dom, presente em potencial no nascimento: “[...] homens que, por terem recebido o dúplice dom da liberdade e da ação, podem estabelecer uma realidade que lhes pertence por direito". Educação e liberdade se encontram na natalidade e a educação, que a princípio faz-se por meio da autoridade e da tradição, e por isso mesmo cumpre com o propósito de educar para a liberdade na medida em que, voltando à definição que a autora empresta à educação, deve preparar as crianças “[...] com antecedência para a tarefa de renovar um mundo comum" (ARENDT, 2000, p. 247).

Ao definir a educação como ponto onde decidimos se amamos o mundo para, assumindo a responsabilidade por ele, salvá-lo da ruína, não fosse a renovação por meio dos novos, Arendt articula ainda o conceito de natalidade - essência da educação, aqui representada pelos novos - com o conceito de responsabilidade. Quando aqui se diz responsabilidade, quer dizer algo muito profundo. Responsabilidade não é culpa, pois esta última é de cunho individual. A responsabilidade é sempre coletiva, vicária. A responsabilidade advém do fato de que nascemos no mundo e para o mundo, e, postos diante dele, somos responsáveis por ele, mesmo não sendo por ele culpados. Nesse sentido, diz Arendt (2004, p. 216-217):

[...] devo ser considerado responsável por algo que não fiz, e a razão para a minha responsabilidade deve ser o fato de que eu pertenço a um grupo (um coletivo), o que nenhum ato voluntário meu pode dissolver [...] somos sempre considerados responsáveis pelos pecados de nossos pais, assim como colhemos as recompensas de seus méritos.

Dessa maneira, assumir a responsabilidade pelos novos é assumir a inalienável e coletiva responsabilidade pelo mundo, posto que somente resguardando a novidade imprevisível - não aquelas que inculcamos nas crianças, e que por sermos velhos também são velhas - salvar-se-á o mundo da ruína.

Além disso, há na definição uma menção implícita ao conceito de autoridade. Quando Arendt diz ser a educação o ponto onde decidimos se amamos as crianças para não deixá-las abandonadas a seus próprios recursos, banindo-as do nosso mundo, ela contrapõe-se à

fortes nesse sentido: "Em A Cidade de Deus, Agostinho, como é mais que natural, fala mais do pano de fundo das experiências especificamente romanas do que em qualquer outra de suas obras, e a liberdade é concebida aqui não como uma disposição humana íntima, mas como caráter da existência humana no mundo. Não se trata tanto de que o homem possua a liberdade como de equacioná-lo, ou melhor, equacionar sua aparição no mundo, ao surgimento da liberdade no universo; o homem é livre por que ele é um começo e, assim, foi criado depois que o universo passara a existir: [initium] ut esset, creatus est homo, ante quem nemo fuit. No nascimento de cada homem esse começo inicial é reafirmado, pois em cada caso vem a um mundo já existente alguma coisa nova que continuará a existir depois da morte de cada indivíduo. Porque é um começo, o homem pode começar; ser humano e ser livre é uma única e mesma coisa. Deus criou o homem para introduzir no mundo a faculdade de começar: a liberdade" (ARENDT, 2000, p. 216, grifo meu). 
educação progressiva que, sob o argumento de que as crianças possuem um mundo autônomo do mundo adulto, abandonam-nas nesse mundo infantil, no qual a criança não pode contar com a solidariedade de seus pares, configurando-se numa ditadura da maioria.

Por vários momentos, em $A$ crise na educação, Arendt se referirá à crise de autoridade. Para ela, a responsabilidade pelo mundo assume, na educação, a forma de autoridade. Esta, por sua vez, é recusada pelo adulto, que recusa igualmente a responsabilidade pelo mundo. A crise de autoridade é intimamente ligada à crise da tradição, isto é, "com a crise de nossa atitude face ao âmbito do passado" (ARENDT, 2000, p. 243).

Cabe aqui, um breve esclarecimento: Arendt (2000) não defende a autoridade na esfera pública, da ação, mas não a dispensa das relações pré-políticas, tais como a criação de filhos e a educação; daí a relevância da autoridade em seus escritos educacionais.

Não se pode entender, aqui, autoridade e tradição com os ranços advindos das aporias da escrita política, que ressignificam termos dando-lhes sentidos por vezes contraditórios. Quanto à autoridade, é comum identificá-la com modelos tirânicos, o que é falso. Arendt faz, em Que é autoridade, a seguinte distinção:

Por de trás da identificação liberal do totalitarismo e do autoritarismo, e da concomitante inclinação a ver tendências "totalitárias" em toda limitação autoritária, jaz uma confusão mais antiga de autoridade com tirania e de poder legítimo com violência. A diferença entre tirania e governo autoritário sempre foi que o tirano governa de acordo com seu próprio arbítrio e interesse, ao passo que mesmo o mais draconiano governo autoritário é limitado por leis. Seus atos são testados por um código que, ou não foi feito absolutamente pelo homem, como no caso do direito natural, dos mandamentos divinos ou das idéias platônicas, ou, pelo menos, não foi feito pelos detentores efetivos do poder. A origem da autoridade no governo autoritário é sempre uma força externa e superior a seu próprio poder; é sempre dessa fonte, dessa força externa que transcende a esfera política, que as autoridades derivam sua "autoridade" - isto é, sua legitimidade - e em relação ao qual seu poder pode ser confirmado (ARENDT, 2000, p. 134).

Nem autoridade é compatível com tirania, nem tradição é exatamente o mesmo que passado. Com a perda da tradição não se perde o passado, mas se perde "o fio que nos guiou com segurança pelos vastos domínios do passado" (ARENDT, 2000, p. 130). A tradição, a despeito da errônea identificação com a religião, não é o passado, mas a memória, que resguarda a profundidade da existência humana. Sem memória, sem recordação, não há profundidade. Ficamos, assim, ameaçados pelo esquecimento.

Se a responsabilidade se traduz, na esfera da educação - considerada por Arendt como pré-política - como autoridade, isso significa que sobre o educador repousa uma legitimidade que não é dele, mas vem do mundo ao qual representa, sendo sua função apresentar aos novos 
o mundo para que, aparelhados do velho, possam ao cabo do processo educativo reconhecerse novos de fato. O educador é, então, representante da tradição, pois não permite que a memória se esvaia em esquecimento. É a educação para a tradição que pode manter a possibilidade do novo, isto é, a liberdade.

Nossa esperança está pendente sempre do novo que cada geração aporta;
precisamente por basearmos nossa esperança apenas nisso, porém, é que
tudo destruímos se tentarmos controlar os novos de tal modo que nós, os
velhos, possamos ditar sua aparência futura. Exatamente em benefício
daquilo que é novo e revolucionário em cada criança é que a educação
precisa ser conservadora; ela deve preservar essa novidade e introduzi-la
como algo novo em um mundo velho, que, por mais revolucionário que
possa ser em suas ações, é sempre, do ponto de vista da geração seguinte,
obsoleto e rente à destruição (ARENDT, 2000, p. 243).

Arendt (2000) também tece comentários a respeito da rejeição da sociedade moderna em relação à distinção entre o público e o privado, causada pelo advento da esfera social, trazendo isso como elemento da crise geral que se sobrepõe à educação. Para que se compreenda essa esfera social, é preciso visitar A condição humana. Arendt (1995) concebe a democracia grega, a pólis, como uma das comunidades políticas mais loquazes em referência à participação política e um momento político privilegiado na história. Não é interesse aqui retomar as propriedades da democracia grega com um olhar nostálgico, mas entender o movimento que a autora verifica na transposição das esferas da vida humana e como isso ressignifica os termos "política" e "público".

Na pólis, a esfera pública e a esfera privada eram bem definidas. A esfera privada era uma esfera pré-política: é a unidade da família, onde a relação do chefe com os demais membros é uma relação despótica. Na família, a relação entre seus membros é desigual. É na esfera privada que se concentram os esforços de manutenção da vida individual; é no núcleo familiar que se cuida das necessidades vitais. Já na pólis, na esfera pública, a relação entre seus membros era relação de iguais, relação entre homens livres, isto é, os sujeitos liberados das necessidades. Aliás, era a vitória sobre as necessidades da esfera privada uma condição natural para a liberdade na pólis.

No mundo moderno, perde-se essa distinção entre a esfera pública e a esfera privada. Os interesses da vida privada, suprir as necessidades vitais, invadem a esfera pública. Segundo Arendt, desta elevação das preocupações privadas ao status de interesse público emerge a esfera social: "O que chamamos de 'sociedade' é o conjunto de famílias economicamente organizadas de modo a constituírem o fac-símile de uma única família 
sobre-humana, e sua forma política de organização é chamada nação" (ARENDT, 1995, p. $38)$.

No mundo moderno, os interesses privados assumem importância pública, haja vista que a ação política, dantes voltada para o interesse comum, maior que o interesse pessoal da subsistência, que era dada no mundo público como já vencida, volta-se inteiramente às necessidades. Vide o quão os discursos econonomicistas, que representam os interesses privados das classes dominantes, pesam fortemente sobre as decisões dos "políticos profissionais".

Nesse contexto, Arendt exprime o significado de política, modernamente falando: a política torna-se uma “função na sociedade". Deste modo, as esferas social e pública possuem menor diferenciação que as antigas esferas pública e privada. Ressignificada a política, igualmente ressignificada a ação política. A ação é substituída pelo comportamento. Diz Arendt (1995, p. 50):

Um fator decisivo é que a sociedade, em todos os seus níveis, exclui a possibilidade da ação, que antes era [a exclusão] exclusiva do lar doméstico. Ao invés de ação, a sociedade espera de cada um de seus membros um certo tipo de comportamento, impondo inúmeras e variadas regras, todas elas tendentes a "normalizar" os seus membros, e fazê-los "comportarem-se", a abolir a ação espontânea e a reação inusitada. [...] O surgimento da sociedade de massas [...] indica apenas que os vários grupos sociais foram absorvidos por uma sociedade única, tal como as unidades familiares haviam antes sido absorvidas, por grupos sociais; com o surgimento da sociedade de massas a esfera social atingiu finalmente, após séculos de desenvolvimento, o ponto em que abrange e controla, igualmente e com igual força, todos os membros de determinada comunidade.

Com a breve exposição acima, dá para perceber que há, na análise feita por Hannah Arendt sobre a educação, um arranjo conceitual bastante amplo que envolve o todo de sua obra. Agora, passemos à crítica ao Pragmatismo, na ótica da autora.

\section{Da crítica arendtiana ao Pragmatismo}

Antes de expor a crítica arendtiana ao Pragmatismo, cumpre fazer alguns esclarecimentos. Arendt (2000, p. 238) não considera que os efeitos dos pressupostos que o envolvem sejam fruto da intenção dos pragmáticos, ressaltando inclusive que "o objetivo central [...] foi o bem-estar da criança", mesmo não tendo logrado êxito e sim resultado em grave violação ao desenvolvimento das crianças.

Por pelo menos dois momentos no texto, Arendt (2000) deixa claro que seu alvo é a “educação progressiva”. Isso, por si só, já é indicativo de que seu embate possui John Dewey 
(1859-1952) como principal interlocutor dentre os autores da primeira geração do Pragmatismo. Além disso, como salienta Renato Rodrigues Kinouchi (2007, p. 220) "Dewey se tornou a principal figura do pragmatismo no século XX. Na verdade, Peirce e James, que faleceram antes da primeira guerra mundial, ainda eram homens do século XIX”.

O problema da crise na educação norte-americana é apresentado por Arendt (2000) como fracasso ou renúncia do ser humano em relação à busca de respostas, pois esse juízo é o bom senso ou "senso comum em virtude do qual nós e nossos cinco sentidos estão adaptados a um único mundo comum a todos nós" (ARENDT, 2000, p. 227). A perda desse juízo é visível na "radical revolução em todo o sistema educacional", que sob o espectro de uma educação progressiva, promoveu a derrubada súbita de "todas as tradições e métodos estabelecidos de ensino e aprendizagem”, entre os anos de 1930 e 1950. “[...] o fato importante é que, por causa de certas teorias, boas ou más, todas as regras do juízo humano normal foram postas de parte" (ARENDT, 2000, p. 227).

O fato de a educação estadunidense apresentar baixos padrões instrucionais em relação aos países europeus está envolto no paradoxo de serem os EUA um dos países mais modernos do mundo; o avanço norte-americano converte-se, paradoxalmente, em retrocesso no campo da educação. Isso é verdadeiro porque:

Em parte alguma os problemas educacionais de uma sociedade de massas se tornaram tão agudos, e em nenhum outro lugar as teorias mais modernas no campo da Pedagogia foram aceitas tão servil e indiscriminadamente. Desse modo, a crise na educação americana, de um lado, anuncia a bancarrota da educação progessiva e, de outro lado, apresenta um problema imensamente difícil por ter surgido sob as condições de uma sociedade de massas e em resposta às suas exigências (ARENDT, 2000, p. 227-28)

Como se pôde notar, a autora considera a educação progressiva como um dos modernos fatores da crise educacional. Nesse particular, entra em cena a crítica ao Pragmatismo. Voltando àqueles pressupostos básicos das medidas equivocadas que levaram a educação à situação de crise: quando não era causado pela influência do posicionamento pragmático, como no caso do primeiro pressuposto, era, em todo caso, ratificado por ele. Isso faz de tais pressupostos reflexos do Pragmatismo na educação. Com respeito a isso, Arendt (2000, p. 233) diz que "qualquer que seja a validez da formula pragmática, [...] tende a tornar absoluto o mundo da infância exatamente da maneira como observamos no caso do primeiro pressuposto básico". 
O primeiro pressuposto, o da existência de um mundo e uma sociedade infantis autônomos ${ }^{3}$, embora Arendt (2000) não atribua a origem ao Pragmatismo, é endossado por Dewey em afirmações tais como: “A instrução consciente só terá possibilidade de eficácia na medida em que se harmonizar com o procedimento daqueles que constituem o ambiente social da criança”" (DEWEY, 1979, p. 19, grifo meu). E ainda: "É importantíssimo encarecer o valor das primeiras experiências dos imaturos [...] Mas estas experiências não consistem em um material exteriormente apresentado e sim na ação recíproca das atividades inatas e do meio" (DEWEY, 1979, p. 86, grifo meu). As críticas elaboradas por ela a esse pressuposto encaminham-se em duas frentes, sendo uma em relação à criança e outra em relação aos adultos.

Quanto aos adultos, Arendt (2000) objeta que a autoridade do adulto, que diz à criança individual o que é devido ou não fazer, é transferida ao grupo de crianças, uma vez que "tudo o que o professor pode fazer é modificar os estímulos e as situações” (DEWEY, 1979, p. 199), gerando uma situação de impotência do adulto ante cada criança. "As relações reais e normais entre crianças e adultos, emergentes do fato de que pessoas de todas as idades se encontram sempre simultaneamente reunidas no mundo, são assim suspensas" (ARENDT, 2000, p. 230). Cabe ao adulto, tão somente, sugerir à criança que faça o que lhe for agradável.

Quanto às crianças, a objeção de Arendt (2000, p. 231) vai no sentido de denunciar os efeitos patológicos da transferência da autoridade sobre a criança individual da pessoa do adulto ao grupo de crianças, efeitos esses que conduzem ao "conformismo ou delinqüência juvenil, e freqüentemente a mistura de ambos". Segundo ela, a autoridade de um grupo sempre é mais forte e tirânica do que a de um indivíduo tomado isoladamente. Se antes a criança lutava contra o adulto, ao menos podia contar com a solidariedade das outras crianças; mas quando a criança está submetida à autoridade de seu próprio grupo, "encontra-se na posição, por definição irremediável, de uma minoria de um em confronto com a absoluta maioria dos outros" (ARENDT, 2000, p. 230). Desse modo, a criança individual perde, quase que totalmente, a possibilidade de insurgência contra essa maioria.

ao emancipar-se da autoridade dos adultos, a criança não foi libertada, e sim sujeita a uma autoridade muito mais terrível e verdadeiramente tirânica, que é a ditadura da maioria. Em todo caso, o resultado foi serem as crianças, por assim dizer, banidas do mundo dos adultos. São elas, ou jogadas a si mesmas, ou entregues à tirania do próprio grupo, contra o qual, por sua

\footnotetext{
${ }^{3}$ Arendt parece não conhecer a sistematização da historicidade do conceito de infância, inaugurada apenas em 1960, na divulgação dos estudos pioneiros de Ph. Ariès, na França, mas que só será publicado efetivamente em 1973, em uma versão modificada e prefaciada pelo autor. A respeito dessa historicidade, ver ARIÈS, Ph. História social da infância e da família. 2. ed. Rio de Janeiro: Guanabara, 1986.
} 
superioridade numérica, elas não podem se rebelar, contra o qual, por serem crianças, não podem argumentar, e do qual não podem escapar para nenhum outro lugar por lhes ter sido barrado o mundo dos adultos (ARENDT, 2000, p. 231)

O segundo pressuposto, que tem a ver com o ensino, toma a pedagogia como "ciência do ensino em geral a ponto de se emancipar inteiramente da matéria efetiva a ser ensinada" (ARENDT, 2000, p. 231). Para a autora, esse pressuposto é influenciado pela Psicologia moderna e por "princípios do Pragmatismo".

Parece haver sólidos indícios, em Dewey (1979), que a crítica de Arendt é dirigida a ele. Para o norte-americano, o ensino "consciente" não é capaz de educar utilizando-se de conteúdos, ou fazendo com que o saber elaborado pela tradição seja transmitido para as novas gerações. Vale ressaltar que não se trata, para Dewey, de uma reformulação didática para que o mundo seja apresentado aos novos, mas de plena recusa, como ele próprio diz, à "galharia seca do passado", ao "estorvo", à “mera tradição".

Vejamos o que ele defende como função da escola:

A primeira função do órgão social que denominamos escola é proporcionar um ambiente simplificado. Selecionando os aspectos mais fundamentais, e que sejam capazes de despertar reações por parte dos jovens, estabelece a escola, em seguida, uma progressão, utilizando-se dos elementos adquiridos em primeiro lugar como meio de conduzi-los ao sentido e compreensão real das coisas mais complexas. [...] Em segundo lugar, é tarefa do meio escolar eliminar o mais possível os aspectos desvantajosos do ambiente comum, que exercem influencia sobre os hábitos mentais. Cria um ambiente purificado para a ação. [...] Toda sociedade vive atravancada, comumente, com a galharia seca do passado e com outras coisas verdadeiramente perniciosas. É dever da escola omitir tais coisas do ambiente que proporciona, e deste modo fazer com que se neutralize sua influência no âmbito social comum. [...] À proporção que a sociedade se torna mais esclarecida, ela compreende que importa não transmitir e conservar todas as suas realizações, e sim unicamente as que importam para uma sociedade futura mais perfeita. [...] Em terceiro lugar, compete ao meio escolar contrabalançar os vários elementos do ambiente social e ter em vista dar a cada indivíduo oportunidade para fugir às limitações do grupo social em que nasceu, entrando em contato vital com o ambiente mais amplo. (DEWEY, 2009, p. 21-22, grifo meu).

Em diversos momentos, Dewey (1979, p. 19) demonstra sua descrença quanto ao ensino por conteúdos, uma vez que para ele "O que o ensino consciente pode fazer é, no máximo, libertar as aptidões". Isso surte efeitos sobre suas concepções de matéria de estudo e do papel do docente.

A matéria de estudo são os fatos observados, recordados, lidos, discutidos, e idéias sugeridas no desenvolver-se de uma situação que tenha um objetivo. [...] O papel do educador na empresa da educação é proporcionar o 
ambiente que provoque reações e respostas e dirija o curso do educando. Em última analise, tudo que o educador pode fazer é modificar os estímulos ou as situações, de modo que das reações resulte o mais seguramente possível a formação de desejáveis atitudes intelectuais e sentimentais. (DEWEY, 1979, p. 199, grifo do original).

E ainda:

Do ponto de vista do professor, os vários estudos, as diversas disciplinas ou matérias representam recursos eficazes, capital utilizável. Não é, todavia, só aparente o distanciamento, desses estudos, da experiência dos jovens: é real. A matéria do estudante não é, por essa razão, nem o pode ser, idêntica à matéria formulada, cristalizada e sistematizada pelo adulto, isto é, do modo que se encontra em livros, obras de arte, etc. [...] O professor não se preocupa propriamente com a matéria [...] existem mesmo certos aspectos da cultura e preparo superior na matéria - considerados em si mesmos - que servem de estorvo ao ensino eficaz, a menos que a atitude habitual do professor seja a de interesse pela interação da matéria com a experiência pessoal do aluno (DEWEY, 1979, p. 201-202).

Mais adiante, como que em resposta a objeções em relação ao abandono do conteúdo, Dewey (1979, p. 206, grifo do original.) o recoloca, mas em plena consonância com o primeiro pressuposto já advertido: "O cabedal de coisas ouvidas ou lidas tem importância [...] mas somente se o educando dele necessitar e puder aplicar em alguma situação dele, educando" Fica ainda mais patente a separação entre matéria e conteúdo na definição deweyana dada à ciência e ao conhecimento, no contexto da explanação sobre a natureza da matéria de estudo:

Ciência é o nome do saber em sua mais característica forma. Ela representa, de certo modo, o resultado final do aprendizado - o termo deste. O que é conhecido, em tal caso, é o que é certo, seguro, assente, aquilo que dispomos; é antes aquilo com que pensamos, do que aquilo sobre que pensamos. Em sua concepção nobre, conhecimento distingue-se de opinião, da conjectura, da especulação e da mera tradição (DEWEY, 1979, p. 208).

Fica flagrante o desacordo entre Arendt e Dewey em relação à importância da tradição, que para ela não é sinônimo de impureza. A tradição é o que confere autoridade ao professor, e só ela garante sua legitimidade. Sendo a função da escola para Arendt (2000, p. 246) “ensinar às crianças como o mundo é, e não instruí-las na arte de viver”, a escola é, como qualquer outra instituição, legitimada pela tradição, que no currículo escolar é a matéria, o saber elaborado.

Vendo que o segundo pressuposto aparta a ciência de ensinar da matéria, Arendt (2000) enumera seus resultados negativos, valendo-se tanto dos aspectos teóricos quanto das circunstâncias factuais. Primeiro, a negligência na formação dos professores em suas matérias, faz com que eles se encontrem "não raro [...] apenas um passo a frente de sua classe 
em conhecimento" (ARENDT, 2000, p. 231). Em conseqüência disso, os estudantes, já abandonados a si próprios, perdem a referência legitimadora da autoridade do professor. $\mathrm{O}$ "professor não autoritário, que gostaria de se abster de todos os méritos de compulsão por ser capaz de confiar em sua própria autoridade, não pode mais existir” (ARENDT, 2000, p. 231), havendo, na prática, uma contradição fundamental.

O terceiro pressuposto, a substituição da aprendizagem pelo fazer, que Arendt considera como ideal da modernidade e encontrando no Pragmatismo sua expressão conceitual sistemática, é de sistematização deweyana, pois para o pragmático "o conhecimento do curso natural do desenvolvimento sempre se vale de situações que implicam aprender por meio de uma atividade, aprender fazendo" (DEWEY, 1979, p. 204, grifo do original). A ênfase, a exemplo da já referida definição de ciência e conhecimento, é aquilo “com que pensamos", isto é, a forma como o saber é produzido. É isso, certamente, o significado, e nisso repousa a centralidade da noção de "desenvolvimento" na teoria pedagógica pragmática, que impõe à educação um imediatismo:

A idéia do desenvolvimento dá em resultado a concepção de que a educação é um constante reorganizar ou reconstruir de nossa experiência. Ela tem sempre um fim imediato, e, na proporção em que a atividade for educativa, ela atingirá esse fim - que é a transformação direta da qualidade da experiência. (DEWEY, 1979, p. 83, grifo meu).

Para Arendt (2000, p. 232), essa noção de desenvolvimento e esse imediatismo transformaram as instituições de ensino em instituições vocacionais "incapazes de fazer com que a criança adquirisse os pré-requisitos normais de um currículo padrão”.

A aplicação do terceiro pressuposto, a substituição do trabalho (no sentido que arendtiano) pelo brinquedo, também provém de Dewey (1979). Para ele, somente o brinquedo, os jogos e os trabalhos ativos - como montar um objeto a partir da sucata, o que não sai da esfera da brincadeira -, são capazes de produzir "resultados intelectuais" que aproveitem os "impulsos naturais das crianças", ou ainda, correspondem ao "método pelo qual os seres humanos mais jovens assimilam os pontos de vistas dos mais velhos" (DEWEY, 1979, p. 12). Diz Dewey a esse respeito:

[...] quando se tem oportunidade de pôr em jogo, com atos materiais [brinquedos, jogos e trabalhos produtivos], os impulsos naturais das crianças, a ida à escola é para ela uma alegria, manter a disciplina deixa de ser um fardo e o aprendizado é mais fácil. [...] o jogo e o trabalho correspondem, ponto por ponto, aos característicos da fase inicial do trabalho de aprender, que consiste [...] em aprender como fazer as coisas e processos aprendidos ao fazê-los. [...] O problema do educador é fazer que os alunos se dediquem de tal modo a essas atividades (DEWEY, 1979, p. 214-216). 
Para Arendt (2000, p. 233), essa solução pragmática coloca em cheque o propósito da educação, que é preparar a criança para o velho mundo dos adultos, posto que o hábito do trabalho, que gradualmente retira a criança do mundo infantil e a introduz no mundo adulto, "é extinto em favor do mundo da infância".

\section{Considerações finais}

Em virtude do exposto, é possível inferir que a raiz teórica da crise constatada por Arendt é a não percepção de Dewey de que o ambiente social da criança não é natural. Nesse sentido, o naturalismo deweyano é expressão conceitual da crise na educação. Ao ratificar a existência de um mundo infantil e desenvolver um método cuja essência é atuar nesse mundo e fazer do educador um mero estimulador, ou seja, reforçando ao máximo que o mundo dos adultos está para a educação apenas como "capital utilizável" a fim de que o estudante possa aplicar em uma "situação dele, educando", Dewey não se dá conta de que o próprio "ambiente social da criança" é em si artificial.

Essa retenção da criança [em seu próprio mundo] é artificial porque extingue $\mathrm{o}$ relacionamento natural [leia-se essencial] entre adultos $\mathrm{e}$ crianças, o qual, entre outras coisas, consiste do ensino e da aprendizagem, e por que oculta ao mesmo tempo o fato de que a criança é um ser em desenvolvimento, de que a infância é uma etapa temporária, uma preparação para a condição adulta (ARENDT, 2000, p. 233).

É pertinente, enfim, retornar à relação entre autoridade e responsabilidade. É pela primeira que assumimos a segunda; recusar a uma, é esquivar-se da outra. Uma educação pautada na autoridade, não é por isso arbitrária ou tirânica. Em Arendt (2000), o educador cumpre com uma dupla responsabilidade: proteger o mundo daquele que é novo, a fim de preservá-lo da ruína, e inserir a criança paulatinamente no velho mundo do qual é herdeira, sem abandoná-la a si própria, onde ela poderá assumir sua condição de novidade e renovar o mundo, exercendo com responsabilidade a sua liberdade.

\section{Referências}

ARENDT, Hannah. Entre o passado e o futuro. São Paulo: Perspectiva, 2000. . A Condição Humana. 7. ed. Rio de Janeiro: Forense Universitária, 1995. . Responsabilidade e Julgamento. São Paulo: Companhia das Letras, 2004.

DEWEY, John. Democracia e educação: introdução à filosofia da educação. São Paulo: Nacional, 1979.

KINOUCHI, Renato Rodrigues. "Notas introdutórias ao pragmatismo clássico". In: Scientiae Studia, São Paulo, v. 5, n. 2, p. 215-226, 2007. 